of the book is increased by this course, and the subject made more human.

In conclusion, it is perhaps sufficient to say that the treatment is marked throughout by the author's well-known and admirable lucidity of style. Take, for example, the last paragraph in the book discussing the result which follows from the fact that as an extreme case for the green thallium light the periods of 88 per cent. of the vibrating molecules are identical within about one part in two millions.

"If you had a great many clocks, and found that taking their average rate to be correct, not more than one in eight would be wrong by a second in twenty-three days, that would represent the maximum amount of variation which one interpretation of the experiment allows us to admit in the case of molecular vibrations. But would any maker undertake to supply you with a number of clocks satisfying that test? If further, it is considered that the limits we have chosen for the possible variations of molecular vibrations are far too great, we see that though Sir John Herschel's saying that atoms possess the essential character of manufactured articles is still correct, yet no manufactured article approaches in accuracy of execution the exactitude of atomic construction. We may conclude with Maxwell that 'Each molecule therefore throughout the universe bears impressed on it the stamp of a metric system as distinctly as does the metre of the archives at Paris or the double royal cubit of the Temple at Karnac.' ",

\section{TECHNJCAL. ANALYSIS.}

Manual of Chemical Analysis. By E. Prost, D.Sc. Translated by J. C. Smith, B.Sc. Pp. iv +300 . (London: Maclaren and Sons, 1904.) Price 12s. $6 d$. net.

Techno-Chemical Analysis. By Dr. G. Lunge. Translated by A. I. Cohn. Pp. vit I36. (New York: Wiley and Sons; London: Chapman and Hall, Ltd., 1905.) Price 4s. 6d. net.

R. PROST'S manual contains a number of selected methods dealing more particularly with mineral and metal analysis which have been compiled, so the preface states, for the use of the " industrial chemist," and which the author assures us are the result of his own experience or that of specialists with whom he is in touch.

The analysis of mineral products-silicates, phosphates, clays, cements, iron and iron ores, and the assaying of lead, silver, gold, \&c., have been so fully elaborated that no analyst deserving the name would be satisfied without knowing the latest improvements in the methods connected with his own industry. A chemist in an iron works, for example, wants all the information he can obtain from the specialist who has made a minute study of iron and steel analysis, including the character of etched surfaces, and through whose hands a large variety of specimens have passed The same, of course, applies to raw materials and finished products of other manufactures. The works analyst is not a student, and though he may wish to be informed on analysis in general, it is not essential to his business.

Does Dr. Prost's book as a whole fulfil its promise? Whilst there is no doubt that many of the NO. I 846 , VOL. 7 I] methods answer to the description given in the preface, and will be found serviceable to the works analyst, it must be confessed there are also many others which fall short of it. In too many instances there is a lack of descriptive detail, an absence of reference to recent improvements, and the omission of recognised and standard methods. The common fault of this class of book is to be too discursive; to cover too much ground. The small treatise on one subject by an expert like Blair or Ledebur on iron and steel analysis, Brown on gold and silver assaying, Lunge on the alkali manufacture, is the sort of thing one would like to see multiplied.

The writer has no wish to deal unfairly with the manual under review. It is not uniform in character, and if the above criticism applies to certain sections, it is also abundantly evident that other portions have been carefully and conscientiously put together by one who possesses a thorough knowledge of his subject. Moreover, the introduction of mechanical tests, which are too frequently overlooked, is a feature deserving mention. The translator's attention should be directed to the mis-spelling of Stanfurt for Stassfurth, p. 4I, Vollard for Volhard, p. 106, and Spiegal for Spiegel, p. 206. The illustrations suffer very much from the rough surface of the paper.

The name of Dr. G. Lunge on the title page of any book, and especially one connected with technical analysis, would command a careful perusal and a thoughtful judgment. It must be confessed that in the present case the author has not done himself justice. Anyone who purchased the volume in the hope of obtaining practical information on technochemical analysis (the translator's rendering of chemisch-technische Untersuchungsmethoden) would, to say the least, be disappointed.

When it is stated that in 128 small octavo pages, in addition to "general operations," and gas, water, and fuel analysis, the analysis of about eighty technical inorganic and organic products is described, further comment seems superfluous. The subject of glycerine, which comes under the section of soap, may be taken as a specimen of the method of analytical treatment.

"Glycerine is found in large quantity only in toilet soaps. The method of determining it is given here, because it must be examined by itself as an individual commercial article, and the glycerine yield of raw fats in the manufacture of stearin must also be determined. The determination is effected either by oxidation with potassium-permanganate solution in alkaline solution, precipitating the oxalic acid formed as a lime salt, and titrating the latter, or by oxidation with normal potassium-dichromate solution, with the addition of an excess of ferrous sulphate solution of known effective value, and then titrating the dichromate solution."

This occupies half a page, sugar is elaborately treated in four pages, tanning in two and a half, dyeing in as many as seven, mineral oils, vegetable oils, and fats in seven, and so on. The most useful page in the volume is the bibliography of important worlss of reference at the beginning, though it is scarcely worth the price of the book.

J. B. C. 